\title{
Cultura e Patrimônio: A Alimentação e o "savoir-faire" na mercantilização, patrimonialização e outras propostas do turismo e da indústria cultural
}

\author{
Culture and Heritage: The Alimentation and the "savoir-faire" in commodification, patrimonialization and \\ other proposals of tourism and cultural industry
}

\section{Elis Regina Barbosa Angelo}

Universidade Federal Rural do Rio de Janeiro - UFRRJ- Rio de Janeiro - Rio de Janeiro - Brasil

Dolores Martin Rodriguez Corner

Instituto Cervantes de São Paulo- São Paulo - São Paulo - Brasil

Resumo: A alimentação pode ser interpretada a partir da construção da própria história do homem, ou seja, sob vários aspectos, reveladores do habitus de cada grupo. Esse artigo pretende esboçar aspectos socioculturais de construção da gastronomia, por meio da compreensão do seu poder de atratividade ao considerar um território relevante para a apropriação do turismo cultural no que tange principalmente ao olhar dos que a buscam como arte, prazer à mesa, memória dos lugares e sentimentos, mas também tece uma crítica à indústria da moda dos sabores e almeja por meio de uma revisão bibliográfica a partir dos estudos culturais traçar uma ideia de como se encontra a mediação entre a mercantilização e a ideia do patrimônio, entendendo que o gosto pode mudar com a sua globalização.

Palavras-chave: Cultura. Patrimônio. Turismo. Gastronomia.

Abstract: The alimentation can be interpreted from the construction of the history of man, that is, in many ways, revealing the habitus of each group. This article aims to outline socio-cultural aspects of gastronomy building through the understanding of its power of attraction to consider a relevant territory for the appropriation of cultural tourism regarding mainly the look of those who seek it as art, pleasure at the table, the memory of places and feelings, but also weaves a criticism of the fashion industry of flavors and aims through a literature review from cultural studies to trace an idea of how mediation is between the commodification and the idea of heritage, understand the taste You may change its globalization.

Keywords: Culture, Heritage, Tourism, Gastronomy. 


\section{Introdução}

Considera-se a cultura, como resultado da interação da sociedade com o meio ambiente, formada pelos conhecimentos, atitudes, hábitos adquiridos, mesmo porque nesta interação que se estabelece, ambas se modificam. Assim, alimentar-se se torna um hábito para atender às necessidades de sobrevivência, enquanto cozinhar é um ato cultural, pois nele o homem faz suas escolhas, rejeições ou aceitações, segue procedimentos baseados nos preceitos dos antepassados. Dessa forma, compreende-se que a alimentação forma 0 ser biológico de dentro para fora, do invisível, do orgânico ao visível da pele, e também o forma de fora para dentro, do visível do signo, ao invisível da consciência, determinando a identidade social. Cabe ressaltar que o alimento é um produto da cultura, tem uso e consumo condicionados a códigos e regulamentos de caráter sociocultural, pelo qual são estruturados.

Existe uma base estabelecida pela origem e pela família na formação do gosto, definindo o hábito, que será mantido ou não, pois as experiências ocorrem e o hábito alimentar vai incorporando outros sabores. "Assim se poderá descobrir para cada caso particular, de que modo a cozinha de uma sociedade é linguagem onde ela traduz inconscientemente sua estrutura." Esta formação do gosto iniciada na infância, o relevante papel feminino na transmissão dos hábitos com as vivências alimentares vão condicionando o paladar e direcionando-o, perpetuando-se e ficando marcadas na memória, abrindo as portas ao longo da vida para as lembranças. "A cozinha não se faz por decreto, se inventa e se tece mediante acordos e parentescos." Ela, a cozinha, se constitui no próprio habitus de um grupo étnico causando condicionamento e hábito.

Faz parte dessa interpretação, o aspecto religioso das culturas, pois afeta diretamente os costumes, por conter uma série de preceitos de valor simbólico em torno da alimentação. Os hábitos alimentares se constituem em um tema multidisciplinar, uma vez que a alimentação pode ser analisada por diversos aspectos: biológico, social, econômico e cultural. A história da alimentação é mais abrangente que a história dos alimentos, da produção, distribuição, preparo e consumo.

O aspecto cultural da alimentação fala mais de um povo do que se imagina, pois o que se come é tão importante quanto, quando se come, onde se come, como e com quem se come, pois o estudo da alimentação aporta importantes detalhes de um grupo, seja pela escolha de ingredientes, os procedimentos empregados no preparo e até pela condimentação dos pratos. Trata-se de um processo complexo que envolve produção, conformação geográfica, clima, vegetação, solo e relevo, também toda uma história. Outras questões são igualmente importantes neste estudo como os diferentes tipos e graus de acessibilidade ao mercado e suas influências sobre o que vai compor o cardápio.

A palavra "gastronomia" referia-se à cozinha da elite, da corte, particularmente à cozinha francesa, e a cozinha não era considerada gastronomia. Mas, o termo passou a ser empregado para definir o prazer à mesa, como uma arte preparada por poucos e apreciada por aqueles que de alguma forma aprenderam a sentir os sabores requintados. " $A$ gastronomia é estilo de vida, é o resumo do mundo, a diferença entre o prazer de comer e o prazer à mesa.

O prazer de comer é sensação direta de uma necessidade que encontra satisfação." Essa definição de gastronomia mostra a diferença que existe entre o comer, o alimentar-se e o prazer à mesa.

Para que se realize a gastronomia é necessário um especialista, um chef preparado e criativo para a elaboração dos pratos; que prepare o alimento com ingredientes e procedimentos pensados a fim de satisfazer os comensais que saibam valorizar a boa comida. Pode-se dizer que a alta gastronomia, teve origem na França e a Gastronomia surgiu da necessidade dos seres humanos se alimentarem com prazer, por serem onívoros e disporem de uma gama maior de ingredientes que mudam o sabor e de procedimentos que permitem escolher o que vai compor o seu prato. 
A história da alimentação é a historia do homem. A busca de alimentos sempre ocupou um lugar de importância na humanidade, nas relações entre povos, sendo motivo de guerras, disputas e invasões, seja pela fome ou ameaça de fome, pois desde tempos imemoráveis o homem lutou por sua sobrevivência.

A mitologia grega registra a ação de Prometeu ao roubar o fogo dos deuses e entregá-lo ao homem, tornando-o um ser divino, conhecedor do segredo dos deuses e passando a ser artífice da civilização, viabilizando o preparo dos alimentos, antes consumidos crus; ao colocar alguns legumes em água para ferver, o homem inventou o primeiro prato, a sopa e passou de "caçador a gourmet" , conforme definido por Franco, passando com isso a alimentação a ser considerado um produto da cultura.

O alimento passou a ser preparado e condimentado segundo cada cultura para satisfazer além da necessidade de sobrevivência do homem, o seu paladar, o seu gosto, que também começou a criar utensílios variados para armazenar e para facilitar o preparo do alimento, seja para grelhar, assar, fritar ou cozinhar. "A cozinha pode ser compreendida como um processo de civilização, que tenta integrar os alimentos silvestres na cultura e ao modificá-los atua como mediadora entre a natureza, cultura, sociedade e universo".

A natureza oferece os ingredientes que após os procedimentos de preparo e aromatização se tornam um alimento, assim, do cru ao cozido, assado ou frito, após processado o alimento não é mais natureza e sim cultura, representando a própria alma de um povo: "Cada época da história modifica o que se põe no fogão e cada povo come segundo sua alma, antes talvez que segundo seu estômago." (BAZÁN, 1988, p. 128)

Dessa forma, pode-se dizer que o homem não come apenas para saciar a fome, pois a alimentação tem significados múltiplos, "por ser o ato de comer uma necessidade psicológica e não só fisiológica." (RITCHIE, 1986, p.12)

O homem come também por prazer, por hábitos adquiridos, uma vez que a alimentação não é somente nutrição, sobrevivência, mas também é prazer, sabor e memória. A cozinha faz parte do imaginário das pessoas, sendo uma construção simbólica por fazer parte dos hábitos, é também herança cultural, tornando-se difícil mudar as tradições recebidas da mãe ou da avó, pois embora ela se transforme lentamente, torna-se inseparável da cultura.

As mensagens codificadas pela alimentação podem ser notadas nas relações sociais existentes, como as classificações e as divisões de inclusão e exclusão. Os fatores que interferem na escolha e preparo dos alimentos, são marcadamente culturais. "Na alimentação o homem biológico e o homem social ou cultural estão estreitamente ligados e reciprocamente implicados, já que nesse ato pesa um conjunto de condicionamentos múltiplos." (SCHLUTER, 2003, p.16)

Os diversos condicionamentos de ordem social, biológica, econômica, ambiental, entre outros, formam um sistema de representações do grupo. No diálogo estabelecido entre a História Cultural e as diversas áreas de estudos como a Antropologia, a Sociologia, a Filosofia e outras, a questão da alimentação pode ser mais facilmente compreensível como representação e como símbolo. As festas são representações, momento em que afloram "esquemas intelectuais, que criam as figuras graças às quais o presente pode adquirir sentido, o outro tornar-se inteligível e o espaço ser decifrado" (CHARTIER, 1990.p.17)

Os estudos culturais se expandiram recentemente, e com este advento tornou-se possível um aprofundamento nas pesquisas das diversas manifestações culturais, dos costumes, do cotidiano, o chamado estudo "porta adentro". Entre estas manifestações, a cozinha de maneira especial é reveladora de traços que vêm de outras épocas, permeada que se encontra pela história e geografia do lugar.

Esse artigo busca, a partir de uma revisão bibliográfica, repensar os direcionamentos que 0 alimento, o gosto, os sabores e o próprio "savoir-faire" vão sendo transformados em produtos do turismo, 
mercantilizáveis, patrimonializáveis e mesmo mantendo alguns peculiares atributos, venham a partir de uma globalização dos sabores, sendo paulatinamente vulgarizados em termos de produção, de valorização e de transformação em um gosto inexpressivo.

Como aportes teóricos, busca-se nos estudos culturais, esboçar o caminho em que a cultura dos sabores vem sendo transformada em nome de moda, de turismo e mesmo de produção em larga escala dentro dos processos ditos "modernos" da indústria cultural .

\section{A Gastronomia, a Cozinha Étnica e o Turismo:} Algumas ponderações sobre a apropriação e mercantilização dos sabores

Os diversos condicionamentos de ordem social, biológica, econômica, ambiental, entre outros, formam um sistema de representações de um grupo. Após as exclusões, o alimento permitido e preferido, nada mais é que "o lugar do empilhamento silencioso de toda uma estratificação de ordens e contra ordens que dependem de uma etno história, da biologia, da climatologia, da economia regional, da invenção cultural e de uma experiência pessoal".

A alimentação revela a cultura, a origem e os costumes de um povo, enquanto os ingredientes que compõem a mesa são, em geral, os abundantes no lugar, sendo possível afirmar que a cozinha de um país representa a sua natureza, posta na panela. A alimentação é resultado das relações entre a natureza e o mercado de um lugar, em que o homem transforma os produtos naturais em consumo, o que propicia uma análise entre paisagem, terra e cozinha.

A cultura alimentar inclui todos os procedimentos culinários empiricamente passados a gerações seguintes, de práticas, dos saberes acumulados de um grupo étnico. Leva em consideração todos os passos a ela relacionados, desde a produção, distribuição, armazenamento, mercado, as técnicas de elaboração e de condimentação, incluindo o que comemos, como comemos, onde comemos e até mesmo com quem comemos.

Esta cozinha chamada étnica vai identificar as pessoas que fazem parte do mesmo grupo de origem pelos sabores e odores próprios. Além disso, ela funciona como comunicação entre os mesmos, principalmente em se tratando de imigração, sendo que os momentos de saborear seus pratos, presentes na memória, podem representar extremo prazer. A película Ratatouille, um desenho animado, representa muito bem este fato, da existência de um prato de memória, da casa da infância, da cozinha da mãe, quando ao prova-lo, imediatamente um juiz dele se recorda e atribui o premio de melhor prato dos restaurantes de Paris, em um concurso. Tratando-se do ratatouille um simples cozido de legumes e verduras, feito nas cozinhas de pobres, muito bem condimentado, pode ser eleito o melhor por seu sabor despertando uma cena guardada em sua memória. No quadro das memórias alimentares, os pratos da infância, assim como aqueles que despertam um prazer único, jamais desaparecem. Para Joseph Plá "o prazer de comer é uma viagem da memória à infância."

Come-se, o que a mãe prepara e coloca no prato, geralmente gostamos daquilo que ela gostava, do doce ou do salgado, da geleia de manhã ou dos cereais, do chá ou do café, do azeite de oliva (quem é provençal) dos gaffelbitter (quem é escandinavo), de tal forma que é mais lógico acreditar que comemos as lembranças, as mais seguras, temperadas de ternura e de ritos que marcaram a primeira infância.

Portanto, os sabores permanecem na memória e tem um sabor todo especial, marcantes e altamente reconhecíveis pelos que conviveram num mesmo grupo. "Memórias obstinadamente fiéis ao maravilhoso tesouro dos sabores da infância, sabores da felicidade perdida, doces sabores do passado".

Cabe lembrar que os sabores afetivos do lar da infância acompanham a vida das pessoas e são evocados pelo perfume, pela visão ou pelo sabor quando degustados, remetem a um tempo, um momento, pessoas ou situações inesquecíveis. 
Devido ao fato de ser dinâmica a gastronomia, evolui no tempo e no espaço, pelos efeitos da própria produção, das técnicas de elaboração, da condimentação, dos produtos disponíveis, há os que desaparecem como o milhete o sorgo, o panizo e há os que se introduzem como a soja e seus derivados, mais recentemente.

A dieta dos "pobres" foi enriquecida com a introdução da batata e do milho, que se expandiram muito rapidamente, modificando a paisagem do país e causando o desaparecimento de outros cereais importantes usados até então para o sustento da população.

Embora, se possam considerar os valores e costumes implícitos na alimentação como algo que não desaparece nem com o passar do tempo, nem com os câmbios alimentares, eles comporão o imaginário do imigrante em terras estranhas.

Para Dutra (1991), como os hábitos alimentares enraizados são portáveis, eles são levados para outras regiões distantes de sua origem, e no caso dos imigrantes, os condicionamentos de ordem social, biológica, econômica, ambiental, entre outros, formam um sistema de representações do grupo étnico. Isto nos leva a concluir que o paladar, muitas vezes, é o último a se desnacionalizar, a perder a referência da cultura original.

A culinária atua como um dos referenciais do sentimento de identidade: é por acompanhar por estar impregnada nos costumes e hábitos, que ela pode se tornar referencial de identidade em terras estranhas.

O turismo, que se refere a um deslocar-se por outros lugares, compreende não apenas a necessidade de alimenta-se, mas especialmente de provar de outros gostos e sabores para evocar sua finalidade de prazer e conhecimento.

Com a necessidade da alimentação em viagens de turismo, a cozinha étnica surgiu, então, como uma importante opção. "Estamos iniciando o século XXI, o turismo gira em torno de dois eixos fundamentais: natureza e esporte, por um lado e cultura gastronômica de outro. A cultura e a gastronomia são demandas básicas do viajante." (OLIART, 2004:46)
Em viagens, alimentar-se é imprescindível, e geralmente o turista ou viajante busca provar os sabores do local, o que veio a demonstrara a necessidade de se eleger um prato regional em cada território. No entanto, em muitos países, esse prato teve que ser "inventado", criado para atender às solicitações de pratos regionais dos viajantes, nem sempre representando a cozinha do lugar, por ser adaptada. As tradições que parecem ou alegam ser antigas são muitas vezes de origem bastante recente ou mesmo acabaram de ser inventadas. "Tradição inventada significa um conjunto de práticas de natureza ritual ou simbólica que buscam inculcar certos valores e normas de comportamento por intermédio da repetição, implica continuidade com um passado histórico."

A paella, por exemplo, representa a Espanha na cozinha internacional, mesmo sendo apenas um prato cotidiano, feito de um arroz colorido com açafrão com o acréscimo de uma carne ou um legume. Neste caso, os pratos regionais ou nacionais podem trazer bons lucros à população local, não necessariamente com a propriedade de restaurantes, mas pela elaboração de comidas caseiras, de pratos servidos em quiosques de rua. Como exemplo o acarajé da Bahia, o pastel das feiras, os milhos assados ou cozidos, entre os mais procurados.

A criação, arte e manipulação do gosto permeiam a tênue relação com a formação social dos indivíduos. A análise se baseia em pesquisa exploratória bibliográfica com especial atenção a valor simbólico (BOURDIEU, 2000) na elaboração de percepções de escolha social e culturalmente caracterizada.

Seguindo essa hipótese, o gosto pode ser evidenciado como representação cultural das classes sociais (SILVA, WRIGHT, 2005) e orientam as escolhas diante de um universo talhado nas possibilidades individuais e coletivas.

Para uma relação dialógica entre os pensamentos de escolha e valor, temos as premissas de Bourdieu (2000) e Marx (1973) na qual a satisfação é possibilitada mediante 0 valor 
socialmente atribuído ao bem, quando indivíduos "escolhem" pagar pelo valor agregado aos produtos.

Nessa questão, o valor atribuído a determinadas representações do gosto só são possíveis por meio de seus significados social e culturalmente representados na relação capital e simbólica. A percepção do gosto é tangenciada pela construção social dos indivíduos num espaço e tempo de consumo típico de uma forma de classificação do ser social que abrange a identidade versus a padronização. Essa padronização é uma forma de estabelecer vínculos dentro de um sistema social de trocas que ora simbolizam expressões e marcas culturais, ora apenas se diluem na mercantilização mundial do consumo em moda.

Em contrapartida, na busca do poder de atratividade dos espaços e segmentos gastronômicos, a memória dos lugares parece intimamente ligada aos sentimentos, sensibilidades e sabores. "Os lugares de memória nascem e vivem do sentimento que não há memória espontânea, que é preciso criar arquivos, organizar celebrações, manter aniversários, pronunciar elogios fúnebres, notariar atas, porque estas operações não são naturais" (NORA, 1993, p.13)

Considerando as sensibilidades, contrapondose à ideia de capital e de valor agregado, esses arquivos, lugares de memória, são uma forma de buscar nas lembranças os sentidos e o próprio sentimento do momento exato em que as experiências foram definidas. Quando há o retorno ao lugar, ao espaço ou até mesmo às sensações, a memória é ativada e o retorno aos sentimentos parece definido a partir de uma operação imagética temporal.

As sensações definem 0 retorno às experiências que, boas ou ruins são retomadas com os sabores, cheiros e sons. Muitas pessoas sentem o retorno aos lugares cristalizados na memória pelo simples fato de rememorarem por meio de imagens, sons e cheiros os lugares visitados.

O sentido do gosto pode ser compreendido dentro do universo simbólico dos grupos sociais, nos quais se pode dizer que estão condensados os seus significados e sentidos por meio de símbolos, que, dentro do grupo possui uma intencionalidade de traços normativos, ou valores intrinsecamente ligados. Esse sentido é descrito nas ideias e valores de grupos específicos como um ethos de indivíduos pertencentes à mesma sociedade. (BERGER, LUCKMANN, 1978)

O gosto é um sistema simbólico que compartilhado pelo grupo realça estilos, formas e sentimentos comuns. Apesar da troca mundial de produtos alimentícios, bem como a divulgação e modelo de hábitos, costumes alimentares e traços culturais gastronômicos, a ampliação desse movimento seria consequência do desenvolvimento de uma cozinha mundial (GOODY, 1982), que além de modificar as práticas alimentares das mais variadas sociedades vão determinando novos comportamentos que, apesar dos traços locais mantém certa proximidade com um elo comum entre sociedades distintas.

Os sabores, hábitos e costumes são incorporados na vida cotidiana das pessoas por meio do lazer, do turismo e mesmo do comportamento de comer fora, usando restaurantes de gastronomia diversificada como novos hábitos individuais e familiares. O sentido do gosto vai seguindo uma modificação que Goody chama de comportamento da world cuisine.

A gastronomia enquanto segmento vai aprimorando tanto a world cuisine quanto as cozinhas regionais e étnicas e ampliando seu público que, além de turistas, visitantes, moradores e simpatizantes vão definindo novos olhares em outros segmentos como televisão, reality shows entre outros.

Algumas personalidades que começaram a demonstrar a comida como personagem ganham força dentro e fora da televisão. Alguns exemplos como o Chef Gordon Ramsay, que com seus programas de televisão promove um verdadeiro evento gastronômico está ganhando força na busca pelos sabores dos lugares como um modismo mundial.

Carlo's City Hall Bake Shop, outro emergente formador de opiniões gastronômicas da televisão 
também dá um toque de requinte na decoração de bolos, pães e tortas com seus programas de show gastronômico. Ao demonstrar como faz bolos decorados e os vende em sua confeitaria em New Jersey, ele e a família de italianos e descendentes dão um toque étnico ao bairro onde cresceram. No programa Cake Boss, programa, há uma deliciosa junção de bom gosto, requinte e bom humor, tratando dos pratos com sentimento, prazer, dedicação e vida cotidiana. $O$ toque especial de sensações, sentimentos e gostos se encontram intrinsicamente ligado à venda de "sabores" no local.

Outros programas de chefs e gastronomia estão em alta em alguns canais da Discovery communications e vão formando novos apreciadores dos sabores das localidades. A harmonia entre sabor e bom gosto das singularidades de cada povo confere um toque especial à busca pela informação, conhecimento e também por novos padrões de gostos em crescente divulgação dessa world cuisine.

Essas novas percepções da massificação da informação criam, de certa forma, novos consumidores, mais seletivos e exigentes quanto aos sabores, aspectos, visuais e apresentação dos pratos. A percepção do gosto vai alterando-se com a quantidade de elementos dessa nova cozinha e também pela oferta de produtos cada vez mais atraentes.

O turismo cultural amplia seus segmentos e espaços no que se refere à busca de segmentos gastronômicos, especificidades de sabores, odores, visuais, e ao mesmo tempo, dando novos passos no aperfeiçoamento dos grupos dentro do segmento. Restaurantes do mundo todo começam a maratona para acompanhar toda a informação desses novos turistas cada vez mais convencidos da relevância do sabor da viagem. O olhar para o gosto aprimorado na apresentação visual aos poucos define aspectos de seleção dos lugares a serem visitados.
Imagem 1: Pera à Belle Hélène

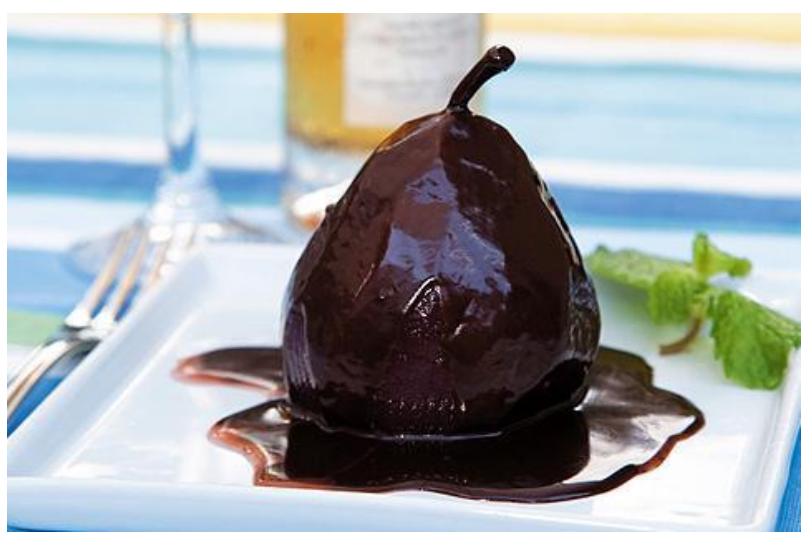

Fonte: Restaurante Afrânio, Araras, Petrópolis, RJ. Disponível em: <http://www.afraniorestaurante.com.br/cardapio.html>

Nas imagens criadas pelos sentidos tem-se a sensação de experimentar um prato saboroso, especialmente pela apresentação visual, na escolha dos ingredientes e na própria construção social do mesmo. A gastronomia propõe isso ao incorporar aos seus restaurantes os novos sentidos dos pratos, onde o prazer à mesa vem da escolha dos ingredientes certos. Esses sentidos são descritos como ethos, conforme dito anteriormente, no que se refere ao pertencimento à sociedade, considerando o gosto como um sistema simbólico que realça estilos, formas e sentimentos comuns.

A formação do gosto se inicia na infância, em geral pela mãe, ou de quem prepara os alimentos, e vai assim condicionando o paladar e direcionando-o, ficando marcado na memória, abrindo as portas ao longo da vida para as lembranças tornando relevante o papel feminino na transmissão dos hábitos e na formação do gosto.

A participação das mulheres na formação do gosto inicia-se com a compra dos ingredientes, com o preparo e condimentação do alimento, causando um condicionamento e um hábito. "A cozinha, tanto ou mais que a língua está organicamente ligada à cultura dos povos e se destaca o papel das mulheres na transmissão das tradições religiosas, culturais e alimentares". (BALTA, 2007, p.54 ) 
O gosto vai depender das ofertas de alimentos e ingredientes feitas na infância, cuja aceitação ou recusa alimentar está ligada aos valores impostos pela própria cultura, segundo o que foi condicionado, portanto ele não é imposto por um governo ou grupo social.

Come-se, o que a mãe prepara e coloca no prato, geralmente gostamos daquilo que ela gostava, do doce ou do salgado, da geléia de manhã ou dos cereais, do chá ou do café, do azeite de oliva (quem é provençal) dos gaffelbitter (quem é escandinavo), de tal forma que é mais lógico acreditar que comemos as lembranças, as mais seguras, temperadas de ternura e de ritos que marcaram a primeira infância. (CERTEAU, 1998. p.249)

A memória cultural permite que não se apaguem as lembranças, os cheiros e o paladar dos pratos da infância. "A importância da memória dos sabores da infância na formação do gosto estará presente por toda a vida." (DUCASSE. 2004. p.189)

A cozinha é cultural, os hábitos alimentares e o gosto são transmitidos de geração a geração de maneira inconsciente, empírica, seja na escolha, na técnica de preparo ou no modo de servir os alimentos, desde a classificação, produção, colheita, conservação, preparo e consumo dos alimentos. Reproduz normas básicas, habilidades e regras culinárias que se interiorizam e refletem nas particularidades de atuação de cada grupo em sua alimentação: "o homem é um animal onívoro que se nutre de carne, de vegetais e do imaginário: na alimentação o homem biológico e o homem social ou cultural estão estreitamente ligados e reciprocamente implicados" (FISCHLER, 1979, p. 01)

O gosto formado na infância permanece na memória e tem um sabor todo especial. "Memórias obstinadamente fiéis ao maravilhoso tesouro dos sabores da infância, sabores da felicidade perdida, doces sabores do passado". (CERTEAU, 1998, p.255)

As palavras: gosto, paladar e sabor apresentam diferenças sutis em seus significados e às vezes se confundem, podendo ser consideradas como sinônimos, conforme o contexto em que são empregadas. Portanto, gosto tem o sentido pelo qual se percebe o sabor das coisas; enquanto o termo sabor emprega a impressão que as substâncias produzem na língua ou propriedade que tem tais substâncias de impressionar o paladar.

Já o termo paladar tem o sentido anatômico de palato, a região anatômica do céu da boca, sensível ao sabor. O gosto ou paladar define para um grupo social suas escolhas, impõem-se quando se tratam de hábitos às demais manifestações culturais. "É indispensável ter em conta o fator supremo e decisivo do paladar, pois para o povo não há argumento probante, técnico, convincente contra o paladar". (CASCUDO, 1983, p.19)

Considera-se a cultura como resultado da interação da sociedade com o meio ambiente, formada pelos conhecimentos, atitudes, hábitos adquiridos, mesmo porque um modifica o outro, a cultura e o meio ambiente. Assim, alimentar-se se torna um hábito para atender às necessidades de sobrevivência, enquanto cozinhar é um ato cultural, pois nele o homem faz suas escolhas, rejeições ou aceitações, segue procedimentos baseados nos preceitos dos antepassados, pelo gosto já condicionado na infância.

O turismo, a mercantilização do gosto e mesmo a forma de transformar o sabor em patrimônio cultural vão dando espaço cada vez mais para que a indústria dos sabores transforme o singular em plural, em mercadoria sem significado étnico, ou de qualquer outra modalidade de produto ou atrativo.

\section{Patrimônio Imaterial: As formas de} conceber os sabores

Com a ampliação do conceito de patrimônio cultural, o patrimônio imaterial foi considerado como intangível, que representa não só as manifestações artísticas, como a música, a festa, as manifestações folclóricas, entre outros, incluindo também todo o "fazer" do ser humano, ou seja, os saberes e os fazeres da vida cotidiana.

Assim, o patrimônio intangível é efêmero, sendo transmitido oralmente ou de forma empírica 
não havendo, portanto manuais, ou texto explicativos, mas é passado pela observação de costumes, e, na alimentação o "como" fazer, incluindo o "saber-fazer" do preparo dos alimentos da família, como manipular, fazer, provar e até mesmo como portar-se à mesa.

Tendo em vista as dimensões continentais do Brasil, isto produz uma variedade cultural e regional de considerável variedade, o que o torna um país plural, como observa e destaca Lima (1999, p.146), ao dizer que "o país é objeto de um inventário patrimonial onde a culinária se enquadra, conjuntamente com museus, templos religiosos dentre outros atrativos turísticos e de valor nacional. Conhecer seu território é também reencontrar sua memória". Neste contexto, e especialmente por esta diversidade cultural, entender esse processo de alimentação e tudo que nele envolve é uma forma complexa de reencontro com a memória, a história e os sentidos da vida cotidiana.

A ampliação do campo da História com a diversificação dos estudos culturais possibilitou um olhar mais atento aos costumes alimentares, no qual as culturas nacionais ao produzirem sentidos sobre a nação traz a tona de certa forma a identificação e a própria construção das identidades. Esses sentidos estão contidos nas histórias que são contadas sobre a nação, memórias que conectam o presente com o passado e imagens que dela são construídas.

As manifestações culturais são expressas de várias formas por seus habitantes, sendo transmitida entre os contemporâneos pela memória, transmitida de geração a geração, causando identidade e sentimento de pertencimento entre os mesmos. "A cultura, na síntese do pensamento universal, denota crenças, valores e técnicas utilizadas pelos homens e suas inter-relações; é a origem de toda expressão e atividade humana, o repositório final de suas manifestações."

Nas manifestações culturais, as expressões são mantidas e assim representam ou não a transmissão as novas gerações. Muitas vezes os pratos tradicionais de uma região tornam-se referencia do lugar, por sua presença registrada na memória como um atrativo turístico das cidades.
A formação do patrimônio pelo gosto, pela memória olfativa, pelo cheiro e pelo sentimento de pertença forma um elo com a representação do lugar, das pessoas e da imagem que ela produz no outro seguindo essa premissa, Franco (2001, p.325) menciona: "graças à antropologia, sabe-se hoje que a preparação dos alimentos e o comer são também atividades simbólicas que permitem perceber as sociedades e a sua complexidade". Essa complexidade de atos, ações e mesmo gostos vão determinando algumas ponderações acerca da vida dos indivíduos nas diversas sociedades.

De acordo com a UNESCO, a formação do patrimônio cultural imaterial organiza-se pelas representações em conluio com as técnicas, formadas a partir da junção de seus instrumentos, objetos, artefatos e lugares culturais que Ihes são associados e que as comunidades e grupos reconhecem como parte integrante de seu patrimônio cultural, considerando que, é feito a partir da transmissão geracional de grupos em seu ambiente cotidiano.

Ao levar essa premissa em consideração, a formação do aptrimônio faz parte da ideia do que é legado e o que fica após a passagem de muitas gerações de uma mesma linhagem, família, grupo ou comunidade.

Essa forma de manutenção do gosto, do saber-fazer e das técnicas utilizadas se assemelha ao que realmente deve ser mantido, pois, numa era global onde tudo pode ser adquirido por canais de distribuição facilitados, o patrimônio se forma pela insistência em manter algo não exatamente intacto, mas vivo.

Esse viver, em suma, representa o "porque" da continuidade, tornando objetos, coisas, memórias vivas enquanto heranças culturais e essas muitas vezes se mantém pelo simples fato de serem comercializadas.

A ideia de manter algo no tempo é a própria formação do patrimônio cultural, onde se estabelecem relações pessoais, grupais e mesmo de sentidos, ou, ao passo em que formam um "mito" em torno desses sentidos acabam mantendo-se vivos temporalmente e 
isso traz de certa forma um valor atribuído ou definido sobre ele.

A mercantilização de objetos, coisas e mesmo sentidos vai tornando um mundo globalizado como um espaço de patrimonialização do tempo, recrutado a partir do valor que Ihe foi atrelado. O que se vende, por exemplo, em roteiros gastronômicos é a ideia de atrelar aos objetos e sentidos do "savoir-faire" que identificam lugares, grupos e espaços.

Quanto mais valor atribuído, mais comercializável e mantido ficam os objetos de memória. Essa passa a ser uma crítica à indústria de bens rentáveis da cultura, numa verdadeira "indústria cultural", onde os sentidos são (re)inventados para dar seguimento e sentido aos lugares, diferenciandoos dos demais, criando uma ambientação para o consumo.

Ao mesmo tempo, os sentidos gerados pelo savoir-faire também merecem a manutenção, pois encerram em si mesmos a manutenção do que tem valor e foi escolhido para ter sentido geracional.

O patrimônio não pode ser visto como mera mercadoria na contemporaneidade, mas de certa forma, também merece atenção essa direção que toma onde os bens são forçadamente mantidos para o lucro. O resguardar e o preservar dizem respeito à memória do lugar, das pessoas e sentimentos, mas ao mesmo tempo vão tornando-se mercadorias na era do consumo.

Os alimentos e os serviços estão sendo desterritorializados, sendo essa uma das características mais relevantes da sociedade global. Garcia (2003), na qual a manutenção dos sabores por meio da gastronomia local está ligada às populações que criam e mantém a matéria-prima caracterizada por objetos e utensílios próprias do lugar, chamadas de Terroir.

Essa premissa faz da formação dos lugares únicos, mantendo como diferencial aos demais suas características, únicas de cada espaço/território e mesmo de sabores, cheiros e odores, mas não forma ou transforma tudo em patrimônio, esse conceito se aplica e deve ser aplicado apenas na sua história, na sua composição, considerando as referências de
Montanari (2008, p. 183) em que o sistema alimentar contém e transporta a cultura de quem pratica a culinária e é depositário das tradições e da identidade de um grupo.

Para Poulain (2006, p.38) "a patrimonialização contemporânea da alimentação se forma a partir a idéia de que o patrimônio passa do âmbito privado para o público, do econômico para o cultural, transformando as representações sociais e, ao mesmo tempo, um bem comum, que participa a todos sobre 'si mesmo'." As culturas alimentares estão sendo rotuladas de Gastronomia, nomeadas de Patrimônios Gastronômicos Regionais, questão essa que transforma o sentido do que é a formação da herança cultural e das tradições que porventura sejam transformadas em patrimônios algum dia.

\section{Considerações finais}

Ao desenvolver os estudos referentes a alimentação, se vislumbra um mundo desconhecido, uma parte importante revelada pelos hábitos de um grupo, inseridos em sua composição pela geografia e a história do lugar.

Este estudo buscou compreender como os saberes, gostos e memórias da cultura alimentar, da gastronomia e dos sabores acompanham a identificação dos espaços/territórios. Também tenta entender como os sentidos dados a objetos, pessoas e lugares vão sendo transformados em mercadorias dentro da indústria cultural, e da era do consumo contemporânea.

O patrimônio imaterial, ao incluir as formas de criar e manter a alimentação e a cozinha de um lugar promove o novo sentido dado pela viagem, pelo deslocamento e especialmente pelo turismo, no qual as pessoas buscam pelo diferente de cada lugar e essa mensagem está diretamente ligada ao consumo e à patrimonialização das coisas, lugares e objetos.

Mercantilizar é também uma forma de manter, mas a que preço? Será que só se preserva tendo lucro? Questão essa a ser pensada no momento em que a busca pela identificação vai ganhando cada vez mais espaço e como forma de manutenção das 
memórias vivas o mundo vende cada vez mais as suas "diferenças" disfarçadas de sabores, cheiros e mesmo sentidos.

Esse criar de sentidos vai de encontro ao que Hobsbawn e Ranger (1984) chamam de invenção das tradições, ou seja, as tradições um dia forma criadas, mas os seus sentidos não necessariamente passam pela invenção da patrimonialização de tudo que diz respeito de um grupo no tempo e no espaço. O que denomina patrimônio é algo que referencia as temporalidades e a quem pertenceu o significado das coisas, mas transformar tudo em "diferente" do outro para comercialização não define o patrimônio cultural.

O patrimônio é uma forma de manter uma cultura viva, mas ao mesmo tempo não pode se transformar em mercadoria rentável para que a sua preservação e conservação estejam unicamente a "mercê" da mercantilização do tempo e de tudo que nele se concentra, mas, antes de tudo uma forma de manter viva a memória daquilo que representa povos, lugares e histórias relevantes para a sociedade.

\section{Referências Bibliográficas}

ANSARAH, Marilia Gomes dos Reis. Cultura e suas manifestações no cotidiano urbano: aspectos do turismo e do lazer cultural brasileiro. In CORREA, Tupã Gomes (org.) Turismo e Lazer, São Paulo: Edicon, 1996.

BALTA, Paul. Beber y comer en el Mediterráneo. Madrid: Programa de Publicación del Servicio de Cooperación y Acción Cultural de la Embajada de Francia en España. 2007.

BAZÁN, Emilia Pardo. In: QUEIROZ, Maria José. A Comida e a Cozinha. Iniciação à Arte de Comer. Rio de Janeiro: Ed. Forense Universitária, 1988.

BERGER, Peter. LUCKMANN, Thomas. A Construção Social da realidade: tratado de Sociologia do Conhecimento. RJ: Vozes, 1978. 4ae edição.

BOURDIEU, Pierre. A Economia das Trocas Simbólicas. São Paulo, Perspectiva, 2003.

BOURDIEU, Pierre. La distinción. Criterios y bases sociales del gusto. Madrid: Taurus. 1988.

BOURDIEU, Pierre. Les structures sociales de l'économie. Paris, Éditions du Seuil, 2000.

BOURDIEU, Pierre. O poder simbólico. Rio de Janeiro, Bertrand Brasil, 2002.
BRILLAT-SAVARIN. 1998. Cf. também: Renata Braune, Silvia Cintra Franco, O que é gastronomia, São Paulo, Brasiliense, 2007

CAMPORESI, Piero. Hedonismo e exotismo: a arte de viver na época das Luzes. São Paulo: UNESP, 1996.

CASCUDO, Luis da Câmara. História da Alimentação no Brasil. Belo Horizonte: Ed. Itatiaia/USP, 1983.

CERTEAU, Michel de. A invenção do cotidiano 2: morar, cozinhar. Petrópolis: Ed.Vozes. 1998.

CHARTIER, Roger. A História Cultural entre práticas e representações. Rio Janeiro. Difel/ Bertrand, 1990.p.p.16-17.

DÓRIA, Carlos Alberto. Estrelas no céu da boca. São Paulo: Ed. SENAC. 2006

DUCASSE Alain. Diccionario del amante de la cocina, Buenos Aires, Paidós, 2004.

DUTRA, Rogéria. A boa mesa mineira, um estudo de cozinha e identidade. Dissertação de Mestrado. URFJ/Museu Nacional, Rio de Janeiro.1991.

FISCHLER, Claude. Presentation. Communications. nำ31. Seuil. Paris.1979.

FRANCO, Ariovaldo. De Caçador a Gourmet: Uma historia da gastronomia. São Paulo(SP): Senac, 2001.

GARCIA, R.W.D. Reflexos da globalização na cultura alimentar: considerações sobre as mudanças na alimentação urbana. Revista de Nutrição, Campinas, v.16, n4, 2003.

GOMENSORO, Patrícia de. Percepção imaculada. Disponível em: $\square$ www.malaguetacom.slog.com.br $\square$. Acesso em 16/10/2008.

GOODY, Jack. Cooking, cuisine and class. Cambridge, Cambridge University Press, 1982.

HOBSBAWN, Erick; RANGER, Terence. A invenção das tradições. Rio de Janeiro: Paz e Terra, 1984

JAMAL, Salah. Aroma árabe. Recetas y relatos. Barcelona: Editorial Zendrera Zariquiey. 2004

L. MOULIN. In. CERTEAU, Michel de. A invenção do cotidiano 2: morar, cozinhar. Petrópolis: Ed. Vozes. 1998.

LÉVIS-STRAUSS. Apud: POIRIER, Jean. História dos Costumes: O homem e o seu meio natural. Vol.4. Lisboa: Estampa, 2000

LIFSCHITZ. Apud: MENESES, Ulpiano T. B.; CARNEIRO, Henrique. A História da Alimentação: balizas historiográficas. História e Cultura Material. In: Anais do Museu Paulista. Nova série. Vol.5. São Paulo: USP, 1997 
MARTEL. Frédéric. Mainstream, Enquête sur cette culture qui plaît à tout le monde.Paris: Éd. Flammarion, coll. Essais, 2010, 464 p.

MARX, Karl. El capital. Crítica de la economia política. Fondo de Cultura Economica,

México, 1973.

MONTANARI, Massimo. El mundo en la cocina. Historia, identidad, intercambio. Buenos Aires: Paidós Diagonales, 2008.

MONTANARI, Massimo. La comida como cultura. Gijón: Ediciones Trea. 2004.

NORA, Pierre. Entre memória e história: a problemática dos lugares. Projeto História. São Paulo: PUC-SP. N 10, 1993.

PLA. Joseph in MARCH, Lourdes La cocina Mediterránea. Madrid: Ed. Alianza. 1988 "O prazer de comer é uma viagem à memória da infância”.

POULAIN, J.P. Sociologia da Alimentação. Florianópolis. Editora da UFSC, 2006.

RITCHIE, Carlson I.A .Comida y Civilización. Madrid: Alianza Editorial. 1986.

SCHLUTER, Regina. Gastronomia e Turismo. São Paulo: Ed. Aleph. 2003.

SILVA, Elizabeth B.; WRIGHT, David. The judgement of taste and social position in focus group research. In Sociologia e ricerca sociale, n. 76-77, 2005. 